\title{
Document Version Keyword
}

National Cancer Institute

\section{Source}

National Cancer Institute. Document Version Keyword. NCI Thesaurus. Code 193814.

A character string of a word or phrase that describes the document and/or its context.

Keywords help users find documents of interest. 